\title{
Literatura y discurso moral en El copo de nieve de Ángela Grassi Private
}

\author{
Victoria GALVÁN GONZÁleZ*
}

Resumen:

En el presente artículo se ofrece un acercamiento a la obra narrativa de Ángela Grassi (1826-1883), quien desarrolla su actividad literaria en España durante el reinado de Isabel II y que la crítica adscribe a lo que denomina "canon isabelino" o "escritoras virtuosas". Ello implica una manera de concebir el mundo, la literatura y la participación de la mujer en la vida pública y literaria. Aquí nos centramos en una novela de la autora de El copo de nieve (1876), con objeto de establecer las relaciones pertinentes con las vertientes decimonónicas de la novela popular, el folletín y la omnipresencia del ingrediente moral, al que supedita su estructura. Asimismo, se establecerá la relación estrecha de estos elementos con la importancia que adquieren en la obra los libros y la lectura.

Palabras clave:

Ángela Grassi, escritoras virtuosas, narradoras de la domesticidad, canon isabelino, injerencia autorial, novela popular, folletín, novela española del siglo XIX, narrativa femenina.

Ángela Grassi (1823-1883) pertenece a aquella generación de escritoras que inician su andadura literaria en los años cuarenta del siglo XIX, con una clara adscripción al credo estético romántico de

* Profesora-investigadora de la Facultad de Filología de la Universidad de Las Palmas de Gran Canaria. 
corte tradicionalista. La biografía de esta autora - que nace en Italia y se traslada desde muy joven a Barcelona, en donde desarrollará una intensa actividad literaria, dramática, lírica y periodísticacomparte, con otras creadoras de su generación, similares inquietudes $y$, ante todo, una decidida voluntad de ocupar un espacio literario aún reservado a los hombres. El asunto de la escritura femenina, como se sabe, se convertirá en objeto de enconados debates en torno al papel de la mujer en la sociedad contemporánea y al nuevo patrón ideológico burgués. Al respecto, la actitud de escritoras como Ángela Grassi será paradójica al proponer en su obra literaria, por una parte, un modelo femenino que circunscribe su actuación al hogar y, simultáneamente, por otra parte, llevar a cabo en el ámbito de su biografía particular una denodada e intensa labor, que abarca desde la escritura de poesías, de dramas, de novelas, hasta la dirección de un periódico, como el Correo de la Moda, del que fue directora hasta su muerte. Cabe situarla, por tanto, en la órbita de escritoras como Ma. del Pilar Sinués, F. Sáez de Melgar o P. de Biedma, que alcanzan notoria popularidad en los años de transición del Romanticismo al Realismo por la publicación de trabajos en revistas, en periódicos, por la edición de sus trabajos, por los premios literarios que recibieron, entre ellas la propia Grassi (su novela Las riquezas del alma, 1866, fue premiada por la Real Academia Española; La gota de agua, 1873, también recibió el premio Rodríguez Cao), y por las reseñas y estudios ${ }^{1}$ dedicados a ellas por escritores coetáneos.

Como se sabe, no puede entenderse esta proliferación de escritoras en la escena literaria decimonónica sin mencionar los nombres de Carolina Coronado (piénsese en su conocido poema "Libertad": "Pero os digo, compañeras / que la ley es sola de ellos, / que las hembras no se cuentan / ni hay Nación para este sexo" [121]) o de Gertrudis Gómez de Avellaneda, entre otras, que rompen estructuras anquilosadas al reivindicar su derecho a escribir como sus colegas masculinos, e incluso deberíamos retrotraernos más atrás en el tiempo, como al siglo precedente, con los casos notables de J. Amar y Borbón o M. Hickey, entre otras. Este debate continuará a lo largo de la centuria con aportaciones señeras como

1 Por ejemplo, el prólogo que escribió C. Frontaura a Palmas y laureles. Madrid: Librería de Juan y Antonio Bastinos, 1884. Juzga los méritos de Grassi a la par que los de Fernán Caballero, Mme. Girardin o Rosalía. 
las de E. Pardo Bazán, Concepción Arenal o Rosalía de Castro. La afirmación de la identidad femenina a través de la escritura ha sido objeto de tratamiento en diferentes estudios ${ }^{2}$ en los últimos años, en los que se ha intentado sentar las bases de una historia literaria renovada, que necesariamente ha de contar con la participación de un sector postergado por la crítica hasta hace bien poco. Sólo quisiéramos subrayar algunas cuestiones previas antes de acercarnos a la narrativa de A. Grassi. En relación con ella, cabe hacer hincapié no sólo en el hecho mismo de la escritura por parte de las mujeres en el grado señalado líneas arriba, sino también en las circunstancias socioeconómicas y políticas que permitieron este auge. Como ha apuntado la bibliografía crítica, el incremento de la producción al socaire del abaratamiento de los libros, el aumento del poder adquisitivo de cierto público, el liberalismo político, el triunfo del movimiento romántico y el inicio de un movimiento de reivindicación de los derechos de las mujeres en el mundo anglosajón abren nuevos cauces para una nueva literatura, que integra además entre su público a un receptor mayoritariamente femenino. Este último factor se torna imprescincidible para entender la relación entre autor y público en la obra de A. Grassi. Como ha señalado con acierto A. Blanco en torno a la primera mitad del siglo se configura un nuevo mapa literario:

[...] En primera instancia y en términos meramente cuantitativos, el recuperar la novela escrita por mujeres aumenta el

2 Enríquez de Salamanca. C. “Quién era la escritora del siglo XIX?” Letras Peninsulares I (1989): 81-107; Kirkpatrick, S. "The Female Tradition in Nineteenth-Century Spanish Literature." Cultural and Historical Grounding for Hispanic and Luso-Brazilian Feminist Literary Criticism. Ed. H. Vidal. Minneapolis: Institute for the Study of Ideologies and Literature, 1989. 343-370; Kirkpatrick, S. Las Románticas. Escritoras y subjetividad en España. 1835-1850. Tr. A. Bárcena. Madrid: Cátedra, 1991; Sánchez Llama, I. "Representaciones de la autoría intelectual femenina en las escritoras isabelinas del siglo XIX peninsular." Hispania 82.4 (1999): 750-760; Sánchez Llama, Í. “El 'varonil realismo' y la cultura oficial de la Restauración en el fin de siglo peninsular: el caso de María del Pilar Sinués de Marco." Letras Peninsulares 12.1 (1999): 37-64; Simón Palmer, Ma. del C. "La mujer y la literatura en la España del siglo XIx." Actas del VIII Congreso de la Asociación Internacional de Hispanistas. T. II. Madrid: Istmo, 1986. 591596; Simón Palmer, Ma. del C. Escritoras españolas del siglo XIX. Manual biobibliográfico. Madrid: Castalia, 1991. 
corpus novelístico ya que la escritora contribuye a la cultura escrita de la época con un impresionante número de títulos. [...] Sin embargo este acontecimiento empírico añade valiosa información para la aproximación sociológica a la novela del siglo pasado que habiéndose centrado, hasta ahora, en precisar el origen de clase de los lectores de medio siglo ha dejado de lado el importante aspecto de género: la existencia de un público femenino que lee novelas escritas por mujeres. ("Escritora, feminidad"14)

El estudio de la presente novela de Á. Grassi, o de otras coetáneas, está signado por esta premisa, pues sólo a partir de estos fundamentos se explican los recursos narrativos o el mensaje propuesto a las mujeres como naturales destinatarias de este género. Aunque este presupuesto deba matizarse a tenor de la reflexión de $\mathrm{N}$. Catelli (27), quien en un reciente estudio sobre la lectura en la novela moderna desmiente el hecho de la existencia de un numeroso público lector femenino. Los datos históricos confirman que el índice de analfabetismo en las mujeres era ciertamente elevado. A pesar de ello es innegable que en la obra de Á. Grassi las reflexiones morales tienen en mente a la mujer, posible o futura lectora. Sus esfuerzos literarios se encaminaron a la promoción de la educación de la mujer de clase media en una dirección ideológica precisa, la del neocatolicismo antiliberal. A ello hay que sumar la evolución que se produce desde la poesía a la novela en cuanto al género más preferido por estas escritoras a partir de los años cuarenta del siglo XIX, las discusiones sobre el tipo de literatura que debía consumir el público femenino y el propio papel que debía acometer la mujer como creadora. En los estudios realizados hasta el momento, se remarca otro aspecto crucial en la literatura femenina decimonónica, cual es la sujeción a criterios morales (Blanco, "The Moral Imperative"), tanto en lo que se refiere al objetivo que ha de regir la escritura, como en la propia estructura ideológica de las obras creadas. Se cumplen en estas escritoras del medio siglo los criterios del "canon isabelino", que en palabras de Í. Sánchez Llama puede definirse del siguiente modo: "Bajo el término 'canon isabelino' consideramos prácticas culturales que privilegian el contenido virtuoso en la definición de la belleza estética fusionando una lectura conservadora y aristocrática del neoclasicismo con las propuestas más tradicionalistas del movimiento romántico" (6566). Se añaden a la definición del "canon isabelino", la nostalgia de 
antiguas costumbres, la defensa de las instituciones eclesiásticas y monárquicas, un nacionalismo contrarrevolucionario y el rechazo a la cultura impresa francesa traducida a partir de 1833.

En otro orden de cosas, entramos en un elemento constitutivo de la novela femenina de naturaleza doméstica: la preeminencia del modelo de la mujer virtuosa y el ideal de domesticidad, metaforizado como "ángel del hogar". Todo ello inserto en un marco de abundante producción de obras de creación y de tratados, de manuales de conducta que prescriben acerca del comportamiento ideal femenino (piénsese en títulos de Ma. del P. Sinués de Marco como El Ángel del Hogar, 1859; Un libro para las madres, 1877; La mujer en nuestros días, 1879). Esta situación podría hacer pensar en la consolidación del ideal de la mujer doméstica en la sociedad contemporánea, con las subsiguientes consecuencias en el plano de las aspiraciones de la mujer escritora, que ve cómo aumentan sus posibilidades de expresión escrita con una ligera permisividad por parte de la sociedad y cómo puede "transgredir" las exigencias de ésta al permitirle participar en la cuestión, ampliamente debatida, de la educación de la mujer. Pero, por otra parte, se ponen límites a la escritura y a la educación femeninas al circunscribir la actividad literaria a la expresión de los sentimientos y de las emociones, asociados tradicionalmente a la condición femenina, que conforman el ideario estético isabelino, duramente rechazado por la nueva estética realista. Se imponen, de este modo, serias limitaciones a la creación literaria femenina que surge bajo las premisas antes citadas.

$\mathrm{Al}$ margen de otros asuntos de capital importancia, en cuanto al género que nos ocupa, la novela, cabe considerar la evolución de la escritura femenina desde los patrones del folletín y de los melodramas románticos hasta la novela realista, con el ejemplo pionero de Fernán Caballero. Centrándonos en la obra de Á. Grassi, su creación novelística, como la de Ma. del P. Sinués o F. Sáez de Melgar, se enmarca netamente en el modelo de la novela de costumbres y del folletín o del melodrama románticos, con sus inevitables limitaciones. Í. Sánchez Llama (258) alude a la contaminación genérica de su escritura y cita la "textura deformante", expresión a la que acude B. Varela Jácome para calificar la novela popular. Su obra presenta una neta dimensión pedagógica, habida cuenta de su trabajo como maestra e institutriz, con la tímida inclusión de las novedades pedagógicas al uso. Persigue ante todo acabar con la inoculación de las peligrosas doctrinas venidas de Francia a través de una literatu- 
ra instructiva y moral con títulos como El heroísmo de la amistad (1842), El bálsamo de las penas (1864), El lujo (1865), El camino de la dicha (1866), Las riquezas del alma (1866), Los que no siembran, no cogen (1868), La gota de agua (1875), El copo de nieve (1876), El capital de la virtud (1877), Marina (1877), La dicha de la tierra (1881) o Palmas y laureles (1884), con la publicación de poesías, dramas y numerosos artículos en revistas y periódicos especializados en la mujer.

En estas páginas nos proponemos reflexionar acerca de algunos aspectos de la novela El copo de nieve (1876), editada en una etapa de retroceso para el "canon isabelino", a partir del discurso moral y de la centralidad de la literatura en el texto para reafirmar cómo el ingrediente moral preside la construcción de su novela, extrapolable al resto de sus creaciones, como conviene, por otra parte, a la novela de la domesticidad y a las creaciones del "canon isabelino". No conviene olvidar que en los años que escribe Á. Grassi han publicado su obra escritoras como Fernán Caballero, quien había planteado asuntos similares desde una propuesta formal más acorde con el realismo europeo a partir de Balzac o escritores como Galdós, pionero de la renovación novelística en el realismo o autores como Valera, Pereda o Alarcón, que publican obras en la década de los años setenta. Es evidente, a tenor de la bibliografía crítica (Andrés 14-15) sobre ella, que el interés de la obra de Á. Grassi no reside en su contribución innovadora al género de la novela, toda vez que sus obras se integran en el modelo del folletín romántico o de la novela de costumbres (la crítica reciente plantea que la novela realista tiene sus precedentes en estos referentes genéricos a propósito de Fernán Caballero, y, también, de Á. Grassi). Pero conviene no olvidar los factores arriba aducidos para comprender que las circunstancias de partida con respecto a los escritores mencionados no son las mismas y que las limitaciones del género ejercen una presión nada desdeñable que no debe soslayarse. Entre otras razones (véase Simón Palmer), quizá la imperiosa necesidad de ocupar un lugar en el espacio literario explique la excesiva presencia del componente moral, como única vía para el reconocimiento. No sería éste un factor exclusivo de la producción femenina, pues otros creadores y teóricos masculinos suscribieron estos dictados creativos, como Cándido Nocedal, J. Balmes o el Padre Claret.

En El copo de nieve se superpone a la trama novelesca una voluntad didáctica; es decir, se trata de una producción literaria al servicio de una causa con un tono acentuadamente melodramático, que 
pretende transmitir una tesis, cual es el efecto corruptor en la mujer de los folletines franceses, tal y como el editor moderno de la novela, I. Sánchez Llama, ${ }^{3}$ ha apuntado. O, como ha subrayado L. R. Loustau, se trata de una novela de tesis que busca desenmascarar el efecto negativo de una literatura perniciosa e impía. En síntesis, se nos relatan las historias entrecruzadas de dos mujeres, Clotilde y Juana. Ambas pertenecen a clases sociales bien diferenciadas: la primera es hija de una aristócrata que se arruina por amor, al casarse con un pintor de diferente clase social. A pesar del fracaso de sus padres, Clotilde logra recibir una educación esmerada de acuerdo con su posición social merced al trabajo de su madre como institutriz de una rica familia. Clotilde asciende socialmente al casarse con Guillermo. La segunda, Juana, es pobre y dedica todo sus esfuerzos con un trabajo extenuante a ayudar a su hermano adoptivo Miguel, del que se enamora, a materializar sus aspiraciones como pintor, pagándole su viaje a Madrid. Su amor llega a extremos tales como venderse de por vida como sirvienta a una familia de labriegos para costearle a su hermano su estancia en Madrid con el objeto de perfeccionarse en las bellas artes. Los destinos de ambas protagonistas se unen a través de Guillermo, que libera a Juana de su esclavitud al contratarla como ama de llaves de su casa. La llegada a la casa sirve a la autora para exponer los contrastes entre las virtudes de Juana frente a Clotilde, quien, sin ser presentada como una mujer contraria al modelo femenino cristiano, se deja seducir por la literatura folletinesca sentimental de su biblioteca particular. Las heroínas literarias viven vidas apasionadas, amores pasionales, que conducen a Clotilde a dudar de la felicidad de la institución matrimonial, aunque su amor por Guillermo se mantenga intacto. La visita de una tía suya, la marquesa de los Gazules, prototipo de mujer depravada, acompañada de Miguel y procedente de Madrid, desencadena su caída. Surge la atracción entre Miguel y Clotilde, sin llegar a sucumbir a la tentación. La marcha de los foráneos de la casa concluye con un envío de cartas comprometedoras para Clotilde, que al ser descubiertas por Guillermo, a la par que Clotilde duda de su marido, provocan la crisis en la pareja. Coadyuvan a ello las nefastas lenguas de algu-

3 Grassi, Á. El copo de nieve. Edición, introducción y notas de Í. Sánchez Llama. Madrid: Castalia e Instituto de la Mujer, 1992. 51-52. Las citas de la novela remitirán a esta edición. 
nas mujeres del pueblo. Aunque se aclara todo, la paz del matrimonio no es completa, pues es chantajeada por el usurero de Orduña con la pérdida de la herencia de su marido. Concluye felizmente la novela, tras llevar a cabo Clotilde una peregrinación hacia un convento, en donde se redime para su regreso final al hogar, restituyéndose la virtud. La obra termina con la paz matrimonial, intensificada por la llegada de nuevos hijos y por la feliz unión de Miguel y Juana.

Como puede advertirse, el argumento es un digno ejemplo de la literatura melodramática y folletinesca, patrones formales que determinan su estructura. Reproduce, por tanto, los elementos constitutivos de este código; esto es: el amor como elemento catalizador de la trama en el seno de los vínculos familiares, en la relación Clotilde-Guillermo-sus hijos, en las relaciones pasionales entre personajes (Juana-Miguel, Clotilde-Miguel); relaciones tensas entre clases sociales, polaridad ricos-pobres; parca caracterización de los personajes, sometidos a la tesis dominante del libro; imagen estereotipada de la sociedad, pues se parte de una visión rígida de las relaciones sociales; espacios topificados, en la oposición entre los defectos de la ciudad por excelencia, Madrid, y el mundo rural, aunque esta novela rompe con la tendencia general a primar el espacio urbano por encima del rural. Aquí Á. Grassi cifra en el campo todas las virtudes necesarias para expresar su ideal de domesticidad frente a un Madrid corrupto, representado por Miguel, que pierde sus principios morales al dejarse seducir por la vorágine de la gran ciudad y por la tía de Clotilde, la marquesa de los Gazules, prototipo acartonado del vicio y la depravación femeninos; detalles propios del costumbrismo en la descripción de espacios interiores, vestidos, hablas; concepción utilitaria del matrimonio en la visión que de la institución sostiene Guillermo; enamoramientos y pasión romántica en la atracción erótica entre Miguel y Clotilde, con el eventual peligro de una infidelidad conyugal, eje temático sobre el que gira el mensaje moral de la novela; representación del estereotipo del enamorado romántico en Clotilde y Miguel; constantes referencias a las sensaciones de los personajes frente a la ausencia de caracterización; presencia del excurso narrativo, recurso habitual en estas novelas, que se traduce en la constante intervención del autor en la obra a través de monólogos explicativos, comentarios que dirigen la lectura con un innegable propósito didáctico; empleo de otros recursos, como las amplificaciones retóricas, descripciones 
artificiosas, desarrollo lineal de la historia, elisión del perspectivismo narrativo, etcétera.

De todos estos recursos, propios de la novela popular y folletinesca, estudiados por L. Romero Tobar, Baquero Goyanes, J. I. Ferreras o F. Ynduráin, entre otros, nos detendremos para el estudio de nuestra novela en lo que L. Romero denomina excurso narrativo o el sermón artículo de fondo, según E. Baker. Un análisis detenido de las injerencias autoriales proporciona datos imprescindibles para calibrar la ideología y la estructura de la obra. Podría decirse que su construcción se supedita en exclusiva a esta estrategia, que, por otra parte, impide un desarrollo de las posibilidades narrativas dentro de la tradición cervantina, que sí lleva a cabo, por ejemplo, B. Pérez Galdós por esas mismas fechas (no se olvide que en el año de publicación de la novela de Grassi, el autor canario saca a la luz Doña Perfecta, con la que Í. Sánchez Llama, en la moderna edición de la novela ha establecido pertinentes relaciones). Á. Grassi se nutre de los resortes formales del folletín (también del melodrama francés, de la comedia lacrimosa del siglo XVIII, como aduce su moderno editor) para censurar la conducta desviada que la lectura del género suscitaba en las mujeres decimonónicas con el retrato de una mujer pervertida por la literatura, como es el caso de Clotilde. Como se sabe, el autor de esta clase de literatura ${ }^{4}$ tiene en su horizonte encauzar a los lectores en una dirección ideológica concreta, enseñar el camino del bien, que no es otro aquí que el de los valores tradicionalistas y católicos. Desde las primeras páginas de la obra, Á. Grassi invoca al soplo divino de su alma con las siguientes palabras, que constituyen el programa que ha de regir la historia que nos ofrece:

[...] y no te detengas más que delante de la cándida virgen, pálida como las rosas blancas, que suspira por su bien perdido. No te detengas más que delante de la madre que vela junto a su hijo enfermo, o del caduco anciano que sólo ve desolación en torno suyo.

${ }^{4}$ Con respecto a la literatura de consumo escrita entre los años 1840 y 1880, Alicia G. Andreu refiere que puede leerse como un gran manual de conducta dirigido a promover en un público lector femenino una nueva forma de conciencia y de conducta de acuerdo con los valores conservadores de la sociedad española de la época. Véase Andreu, A. G. Galdós y la literatura popular. Madrid: Sociedad General Española de Librería, 1982. 
Detente a su lado, y cuéntales esta breve historia: historia breve de lágrimas, que te ha enseñado a ti cómo debías llevar la Cruz bendita, símbolo de redención, hasta el Calvario, para remontarte desde su alta cumbre, vestido de sol y coronado de estrellas al inmortal seguro.

Corre, soplo divino de mi alma, ve en nombre del espíritu increado a revelar a los que sufren el modo de convertir en rosas las espinas, las lágrimas en benéfico rocío. (67-68)

Desde esta atalaya espiritual la autora diseña una historia en la que primará el modelo de la mujer virtuosa frente a la Eva pecadora; es decir, Juana, la mujer pobre, ejemplar y abnegada, frente a Clotilde, personaje del que se sirve para mostrar en simple antítesis los peligros que acechan al modelo femenino canónico. Ya J. I. Ferreras (La novela 287) hablaba del dualismo moral imperante en esta literatura, del vicio frente a la virtud. La novela serializada ofrecerá en una estructura en blanco y negro la lucha entre el bien y el mal o entre la pobreza y la riqueza. No puede olvidarse la asociación con la novela virtuosa dieciochesca, en la estela de S. Richardson, que en su Pamela o la virtud recompensada muestra los asedios infructuosos del vicio a la virtud con su notable repercusión en la novela española, como la crítica especializada ha apuntado (véase Álvarez La novela y "El modelo"). Puede comprobarse la relación con las novelas de Montengón en Eudoxia, la hija de Belisario, donde se plantean los errores que causa la ociosidad en la mujer, de Martínez Colomer en El Valdemaro, en la que se reprueba el placer y el goce de las pasiones frente a las exigencias morales en el personaje de Felisinda, de Zavala y Zamora en La Eumenia, con la exaltación del amor en el matrimonio y el menosprecio de corte, o de Valladares de Sotomayor en La Leandra, con su interés por presentar un mundo moral dual. Los modelos femeninos propuestos por la novela dieciochesca se sustentan en los valores de la edificación y de la conservación del orden establecido.

Este dualismo maniqueo se convierte en el eje central de la novela de Á. Grassi, sin olvidar las reflexiones iniciales, impregnadas de fatalismo y dolor, puestas de manifiesto en declaraciones del tipo: “ Cuadros disolventes de sombra y luz: he aquí la vida!” (77), en boca de la madre de Clotilde, quien la insta a resistirse al lujo y a los placeres o en la evocación del tópico menosprecio de corte, presente en toda la novela, con los comentarios iniciales de rechazo al ferrocarril, fuente de corrupción para los tranquilos habi- 
tantes de Orduña, de conocidas resonancias en la novela decimonónica, como en los casos de Clarín o de Galdós (recuérdese el primer capítulo de Doña Perfecta, en el que la llegada del tren a la virtuosa Orbajosa supone la irrupción del progreso en clave diabólica que representa Pepe Rey, aunque la conclusión narrativa al conflicto que origina sea harto divergente en ambas novelas por mor de credos estéticos e ideológicos antagónicos). Estas referencias iniciales marcan, y lastran, el desarrollo de la trama posterior, con el añadido de la presencia de la música - se sabe de la composición de libretos de ópera por parte de nuestra autora-, que emana de una flauta, símbolo de la armonía y la conexión entre el alma y el mundo celestial, explicitando al lector los ejes de los que se hará depender tanto la acción como los comentarios de la autora. La música, como la literatura y el arte, en general, se interpreta aquí desde una estética cristiana. No eran ajenos los escritores románticos a esta particular simbiosis, como ha explicado P. Bénichou, para quien:

[...] se añade una estética, que considera lo bello como el sello de Dios en la naturaleza, el universo como un cántico, el arte como un culto, y la palabra poética como el órgano simbólico de las tradiciones universales. [...] En este sentido, el arte cristiano es la clave de todo arte, y la poesía, como "transparencia del ideal a través de las formas de que está revestido", sólo podría tener la religión por principio. (185-186)

De este modo, el lector ya sabrá de antemano que los personajes entregados a los vicios mundanos y a las pasiones rectificarán sus conductas, secundando en ello los modos habituales en la novela didáctica y ejemplar, a modo de moderno exemplum. Así vemos cómo Clotilde será reconducida hacia el patrón de la virtud por medio de la redención, portando su propia cruz, como reza el prólogo ("historia breve de lágrimas, que te ha enseñado a ti cómo debías llevar la Cruz bendita, símbolo de redención, hasta el Calvario, para remontarte desde su alta cumbre, vestido de sol y coronado de estrellas al inmortal seguro" [68]), cuando peregrina fuera de su hogar, ya avanzada la novela, para ser perdonada por toda la sociedad que la condena, a pesar del perdón de su marido. Las palabras preliminares al texto, arriba reproducidas, gravitan tanto en las intervenciones autoriales como en la propia trama o en la caracterización de los personajes. Veamos algunos ejemplos: 


\section{¿Quién era la Marquesa de los Gazules?}

Su historia también se podía contar en dos palabras. Se reducía toda ella a galantes aventuras en las cuales jamás había tomado ni la más mínima parte el corazón, batallas dadas en los estrados con una destreza admirable e insulsas murmuraciones. (159)

[...] En una palabra, para completar el retrato de la noble Marquesa diremos que había obrado exactamente como la cigarra de la fábula, que pasó todo el verano cantando sin guardar nada para el invierno; ella había pasado toda la vida ocupada en cosas frívolas, sin hacer el más mínimo acopio para la otra vida. (161)

Cada siglo tiene su hipocresía; su máscara para ocultar sus vicios; su bandera para justificarlos. La máscara de este siglo son la falsa ilustración y el falso progreso indefinido. El progreso indefinido, que levantó la torre orgullosa de Babel, para producir la confusión y la ruina. Dios ha confiado al hombre, su hijo predilecto, una centella de sus propios resplandores; pero el hombre soberbio que quiere convertirse en Dios, cae precipitado al caos donde residen las tinieblas. (173)

Se patentizan aquí los anatemas lanzados contra el espíritu romántico liberal y contra las ansias de transformación al unir el progreso y la ilustración al caos y la descristianización. Es obvia la adscripción de estas palabras a la axiología romántica tradicionalista, que impulsó la narrativa de Fernán Caballero. Éstas y otras citas de semejante cariz confirman la suscripción de la novela a los dictados de la novela doméstica, portadora de los ideales conservadores, como freno al desarrollo de la subjetividad femenina y como postergación del deseo, que queda en suspenso ante la promesa de una vida plena más allá, al margen de los desafueros del ámbito urbano, símbolo de la caída del hombre. Se cumple, por tanto, el dominio del espacio público por encima del privado. Las convenciones sociales deben presidir el ideal de vida femenino burgués, definido paradójicamnete por su valorización de las iniciativas individuales. Todo ello en oposición a novelas precedentes como $\mathrm{La}$ filósofa por amor, donde F. de Tójar asimila los principios de la moral natural y contempla lo público-social como antinatural. Estos excursos en El copo de nieve afectan directamente a los roles de la mujer como esposa, madre o hija, que coinciden plenamente con las propuestas femeninas de Fernán Caballero en Elia, o en el con- 
junto de sus novelas. Valga como ejemplo el final de Matrimonio bien avenido, la mujer junto al marido, en el que triunfa la mujer casa$\mathrm{da}$, pese a los defectos del esposo.

Por otra parte, cualquier novela de Á. Grassi reproduce con fidelidad el topos, que ella en sus artículos de prensa, Fernán Caballero en sus cartas o Ma. del P. Sinués, entre otras, refrendan. Valgan a modo de ejemplo las siguientes declaraciones de esta última, en Un libro para damas. Estudio acerca de la educación de la mujer (1878):

No pertenezco yo al número de las que creen que la mujeres debemos legislar en los congresos y dictar sentencias en los tribunales; sino que antes bien me parece que la misión de la mujer debe ser realizada en el interior del hogar doméstico. Formar el corazón de sus hijos y llevar sus sentimientos por el amor a lo bello y a lo bueno; ser la consejera íntima, la amiga de su marido; poner en todo lo que la rodea el sello de su bondadosa e inteligente dulzura, he aquí, según mi opinión, el deber social de la mujer de familia. (5-6)

Es absoluta la coincidencia con los artículos publicados en la prensa femenina, como El Correo de la Moda o El pensil del bello sexo, entre otros, con las novelas de las autoras que hacia 1850 escriben novela doméstica y con los numerosos tratados que acerca de la mujer se publicaron. No se añade nada nuevo al afirmar que se trata de un fenómeno del que participan la mayoría de las mujeres escritoras que comienzan a publicar por los años cuarenta en un intento, como se ha afirmado en líneas anteriores, de ser respetadas o convencidas de la necesidad de dirigirse a un público femenino, acostumbrado a las lecturas de novelas foráneas, que proponen en muchos casos modelos de conducta erróneos, en especial las de procedencia gala. En este sentido, la función moral de la literatura se convierte en el eje de estos escritos, objeto de preocupación entre escritores masculinos, como Cándido Nocedal, Donoso Cortés, para quienes la novela debía encauzarse hacia fines morales. En este contexto y desde esta óptica no debían darse ejemplos literarios contrarios a estos designios, salvo excepciones, dado el peso que ejercieron determinados referentes novelescos, como la novela pedagógica, ejemplar o de tesis. De ahí que Á. Grassi convierta el tema de la literatura en uno de los pilares de su novela con discursos que repiten las consignas de moda. Es revelador, al respecto, en 
el análisis de la biblioteca de Clotilde el rechazo de las lecturas de novelas francesas y las funciones que la autora atribuye a la literatura destinada a mujeres, que culmina en la obra con el hecho de arrojar la llave de la biblioteca al fuego, en una acción simbólica que pretende aniquilar los síntomas de la caída de la mujer o la quijotización de Clotilde. Los juicios acerca de la literatura en relación con la función que la mujer ha de cumplir en la sociedad se reflejan en las siguientes palabras:

En efecto, si la literatura de una época lleva su veneno al corazón de la sociedad, luego para ver su eco, retratando los tipos, costumbres y creencias que ve pulular en torno suyo.

Solidarias entre sí, y estrechamente enlazadas, si la sociedad principia a modelarse sobre la literatura, ésta a su vez acaba por modelarse sobre la sociedad, recibiendo simultáneamente la una de la otra inspiraciones y vida, hasta que gastadas las ideas, llegando al abuso las costumbres, una y otra despiertan de su error, efectuándose la reacción, porque el mundo moral es una rueda que gira perpetuamente sobre sí misma; es como las aguas de un río, que después de haber inundado los campos, obedeciendo a una ley ineludible, vuelven a su nivel primitivo.

[...] Y la literatura que debiera ser el faro refulgente que guiase a la humanidad por las serenas vías de lo bello y de lo bueno, se empequeñece y se arrastra, y los escritores, que debieran ser los sacerdotes del bien se convierten en juglares, atentos sólo a divertir a la multitud con sus grotescas farsas. (172 y 174)

Como puede apreciarse, se atribuye a la literatura una función instrumental en clara consonancia con los dictados docentes y morales de buena parte de la literatura dieciochesca, con las voces que en el siglo XIX reclamaban un control de los contenidos de las artes y con la ideología del "canon isabelino", bajo el que se adscribe la obra de Á. Grassi. En este sentido, aparte de coincidir con las ideas del sector tradicionalista, se deslizan planteamientos nostálgicos, como la identificación de la literatura con los conceptos del bien y la belleza, en una suerte de actualización del ideario estético neoplatónico, que hará circular el romanticismo tradicionalista. Al confrontar estas declaraciones con la preceptiva decimonónica (Morales 89) se advierte la omnipresencia de la asociación entre belleza y bien o belleza y verdad. La novela debe elevar y purificar la inteligencia del lector al objeto de expresar la conformidad de la belleza y el bien. 
Si pensamos, por ejemplo, en la obra de Fernán Caballero, considerada por la crítica (Blanco Escritoras y Charnon-Deutsch 15-16) como modelo de las escritoras isabelinas, podrá observarse cómo este prontuario estético se repite en buena parte de sus obras. Por ejemplo, las palabras preliminares de La Gaviota son esclarecedoras, cuando afirma: "[...] porque el objeto de una novela de costumbres debe ser ilustrar la opinión, por medio de la verdad, sobre lo que se trata de pintar, no extraviarla por medio de la exageración" (39-40). Aunque los puntos de partida de ambas escritoras sean diferentes, coinciden en atribuir a la literatura la función de recrear la verdad o el bien. Todo ello tamizado por una ideología concreta, que sitúa las tentativas literarias en el ámbito de la inevitable idealización, contradictoria con las pretensiones iniciales en el caso de Fernán Caballero. Para ésta el principio rector de la literatura ha de ser la búsqueda de la verdad de las costumbres nacionales, en oposición a la imagen desvirtuada que los extranjeros ofrecían de España, en lo que J. Marco denomina costumbrismo como reacción. Pero esta pretensión de veracidad o ese afán por "poetizar la verdad", en palabras de E. Caldera, se trunca por la parcialidad que anima la caracterización de los personajes o por el planteamiento de la trama novelesca. Por otra parte, Á. Grassi, que podría ser de igual modo destinataria de similares juicios críticos, parte de la tesis de modelar la sociedad a partir de la literatura o, dicho de otro modo, de establecer un modelo previo de sociedad, que conduciría a un cambio de actitud y de mentalidad entre los lectores, viejo proyecto con el que sueñan aquellos que creen en la posibilidad de influir en el receptor a través de las artes. En cualquier caso, ambas coinciden en el papel preponderante que confieren a la literatura, como instrumento de persuasión y de acción en la sociedad y en la creencia en el poder de la palabra literaria para modular la conducta de los individuos, que a su vez comparten con buena parte de los escritores coetáneos.

Á. Grassi ha articulado una narración a partir de la presencia de los libros en la vida del personaje, de Clotilde, que representa a la mujer "caída". Su biblioteca determina y define su personalidad, presa de una extrema sensibilidad, agudizada por las lecturas inconvenientes. Éstas incluyen melodramas y novelas francesas, como las de Georges Sand ${ }^{5}$, que le proporcionan un modelo de existencia

${ }^{5}$ El nombre de la escritora gala suscita el rechazo unánime del sector tradicionalista (Véase Schor, George Sand). Aunque para Grassi simboliza el pecado 
alternativo, conformado por una vida amorosa apasionada, entregada por completo a sus pasiones, sin pensar en otras exigencias que no sean las del amor. La injerencia autorial hace recaer la responsabilidad de los desvíos de la protagonista en tales elecciones literarias. Se trata de una ama de casa y esposa que dedica buena parte de su tiempo al ocio estéril, pues se establece la pertinente asociación entre la lectura y el ocio nocivo, culpable de los deseos insatisfechos y peligrosos del personaje, como venía siendo habitual en la narrativa dieciochesca y en la novela de costumbres. El libro, determinado tipo de lectura, constituye una amenaza para el orden familiar y social. Clotilde está caracterizada a partir de sus libros, que se convierten en expresión de una existencia anhelada, deseada, sólo materializable, de momento, en el acto de la lectura. Los libros cumplen una función crucial en la medida en que inundan el universo de los personajes. Son expresión de los deseos no cumplidos y proyectados en la imaginación literaria. En palabras de L. Charnon-Deutsch: "What is desired often is the other: adventure, agency, culture, the outside world, all those things that, according to Jessica Benjamin, the maturing woman associates with the forbidden father" (24). Las lecturas devienen, por tanto, un signo de otra realidad que se superpone a la realidad externa a los libros. En este sentido, los libros ocupan un espacio capital en la narración por cuanto llenan y conforman la vida de los personajes, aportando datos sobre ellos, incluso desconocidos para los propios protagonistas. La lectura permite a Clotilde llevar a cabo una introspección de las partes más ocultas de su personalidad, como cuando declara:

[...] Pero me falta algo: algo que ignoro, pero cuyo nombre encuentro en estos libros, y quizás en el fondo de mi alma. ¿Por qué me habrá regalado Guillermo esta rica biblioteca? Antes tomaba la vida como es en sí: ahora aspiro a hallar otras emociones, otras luchas, otras glorias. (91)

El acto de la lectura se transforma, de esta suerte, en una vía de conocimiento y de experiencia para el personaje, que le permite ingresar en mundos vedados para el ideal de la mujer virtuosa. Puede afirmarse, como apunta N. Catelli, que aquí la representación de la vida es representación de lecturas, a lo que añade:

y la perdición, se desprende de su obra que quizá resultaba más reprobable a sus ojos la propia existencia de la escritora francesa que su obra. 
[...] el horizonte es la frecuentación de los libros. La tendencia a que la biblioteca alcanzase el rango de espacio totalizante se anunciaba, como lo prueban las crónicas que cita Whitmann o las observaciones del doctor Johnson, ya a finales del siglo XVIII; pero sólo obtendrá ese estatuto en la primera mitad del siglo XIX. (58)

Explica N. Catelli cómo a partir de la omnipresencia del libro y de la lectura se modulan los conflictos y los sueños modernos de los espíritus del siglo. Continuará su disertación acerca de la lectura con ejemplos de la literatura decimonónica que rompen con la lectora tradicional y ceden el paso al nuevo modelo de lectora, ausente de la obra de Grassi, que sólo justificará la lectura como acceso a un diseño preestablecido de existencia ante el que no cabe la transgresión, que sí se advierte en personajes como Drácula, Jekyll, Carmen o la nueva mujer lectora presente en Villette de Charlotte Brontë. La lectora de Á. Grassi, por el contrario, metaforiza la confirmación de los valores oficiales de la axiología doméstica e isabelina. En ese periplo por las oscuridades de su interioridad que le proporciona la lectura, Clotilde y la autora optan por el mundo estable y conocido del amor familiar y conyugal, negando otras posibilidades, asociadas a la exaltación de los sentimientos y a sus peligros (pensemos en los riesgos de la sujeción irracional a los propios impulsos y sentimientos en personajes galdosianos como Tristana, Isidora Rufete o en Ana Ozores, que acaban con el fracaso de esta conducta, pero con una lectura opuesta a la de Grassi).

Cabe añadir que Clotilde al principio de la novela se presenta como una fiel seguidora del "bovarismo", que, como ha explicado con acierto D. Pennac, se trata de una enfermedad de transmisión textual, cuyos síntomas son los siguientes:

Satisfacción inmediata y exclusiva de nuestras sensaciones. La imaginación brota, los nervios se agitan, el corazón se acelera, la adrenalina sube, se producen identificaciones por doquier y el cerebro confunde (momentáneamente) lo cotidiano con lo novelesco. (159)

Esa confusión entre lo real y lo novelesco tiene mucho que ver con la omnipresencia de los libros en el universo del personaje, como apunta N. Catelli. No hay otra realidad para Clotilde que la 
que aparece en sus libros. La imagen que le devuelven de su existencia le hace cuestionarse la institución matrimonial hasta el extremo de desear caer en los brazos de Miguel, que materializaría, en caso de producirse la infidelidad, las promesas que guardan los ponzoñosos libros de su biblioteca, como se advierte en las siguientes palabras:

Clotilde experimentó el choque eléctrico de aquellas ardorosas sensaciones; sintió correr por sus venas parte del fuego que corría por las venas de Miguel, el amor desordenado y poético de sus libros se ofreció a su enferma imaginación avasallándola; creyó estar en su derecho, compartiendo aquel amor ideal que ofrecía un bálsamo dulcísimo a sus penas. (189)

Presenta aquí los peligros de esta literatura, asociando la imaginación descontrolada a una enfermedad, que genera una conducta patológica en el personaje. No existe otra posibilidad que la renuncia a los excesos de la imaginación; por tanto, a la libertad creadora y liberadora. Es evidente que la autora a través de las injerencias e intromisiones o de los juicios que desliza en la narración trunca toda posible perspectiva, dirigiendo el discurso hacia un relato de sombras y de luces, de buenos y de malos, como lleva a cabo en otras novelas suyas. La preocupación por el tipo de lecturas y de educación que ha de recibir el género femenino es una prioridad para escritoras como Á. Grassi, enemiga acérrima de la literatura libertina francesa de Georges Sand o de otros escritores afines. Asimismo, la responsabilidad recae en los escritores, a quienes acusa Grassi de no estar a la altura del sagrado ministerio que ejercen. No se olvide que habla del arte literario como sacerdocio y exige a la literatura que responda a las leyes de la moral. En cualquier caso, para escritoras como Grassi el trayecto hacia el bien y la virtud pasa por la lectura. Con ella quiere pergeñar el cuadro de las expectativas de la mujer burguesa, a la que aguardan como madre y esposa unas responsabilidades, puestas en peligro por el desorden (los peligros del lujo, en su novela homónima; la conveniencia del vivir abnegado o el desprecio de los bienes materiales en beneficio de las virtudes domésticas en El capital de la virtud) y el caos de la sociedad materialista e impía del presente. De ahí, la visión negativa y pesimista que atraviesa toda su obra, apreciable en esta novela en distintos momentos. Por tanto, para la empresa de la regeneración moral la literatura ha de cumplir una función nuclear 
al objeto de evitar la caída, como se aprecia en las siguientes palabras de C. Gimeno de Flaquer:

La mujer que se apasiona por ciertas novelas, se crea mundos ignotos y encuentra muy desagradable el planeta que habitamos. Acostumbrada a las brillantes escenas que el pincel del autor le ofrece, a las vivas emociones, a las bellezas sorprendentes, a los rasgos heroicos, a las pasiones gigantescas, a los sucesos extraños y a la poesía que circunda de flores cuanto toca, encuentra la vida real muy mezquina.

Como en los ideales mundos de la novela todo es hiperbólico y ardiente, en nuestro mundo sólo halla frialdad, desencanto, desilusión. (267)

\section{Bibliografía}

Álvarez Barrientos, J. La novela del siglo XVIII. Madrid: Júcar, 1991.

_. "El modelo femenino en la novela española del siglo XVIII." Hispanic Review 63.1 (1955): 1-18

Andrés, Ramón. “Ángela Grassi, memoria y minoría.” Ínsula 516 (1989): 14-15.

Baker, E. Materiales para escribir Madrid. Literatura y espacio urbano. De Moratín a Galdós. Madrid: Siglo XXI, 1991. 100.

Baquero Goyanes, M. “Filtraciones del folletín." Proceso de la novela actual. Madrid: Rialp, 1963.

Bénichou, P. El tiempo de los profetas. Doctrinas de la época romántica. México: Fondo de Cultura Económica, 1984. 185-186.

Blanco, Alda. "The Moral Imperative for Women Writers." Indiana Journal of Hispanic Literatures 2.1 (1993): 91-110.

—. "Escritora, feminidad y escritura en la España de medio siglo." Breve historia feminista de la literatura española (en lengua 
castellana). v. La literatura escrita por mujer (Del siglo XIX a la actualidad). Coordinado por I. M. Zavala. Barcelona: Anthropos, 1998.

. Escritoras virtuosas: narradoras de la domesticidad en la España isabelina. Granada: Colección Feminae, Universidad de Granada, 2001.

Caballero, F. La Gaviota. Edición de C. Bravo-Villasante. Madrid: Castalia, 1984. 30-40.

Caldera, E. "Poetizar la verdad" en, Fernán Caballero. Romanticismo 3-4 (1988): 17-22.

Catelli, N. Testimonios tangibles. Pasión y extinción de la lectura en la narrativa moderna. Barcelona: Anagrama, 2000.

Coronado, C. Antología poética de escritoras del siglo XIX. Edición de S. Kirkpatrick. Madrid: Castalia, Instituto de la Mujer, 1992. 121.

Charnon-Deutsch, L. Narratives of Desire. Nineteenth-Century Spanish Fiction by Women. Pennsylvania: The Pennsylvania State University Press, 1994.

Ferreras, J. I. La novela por entregas. 1840-1900. Madrid: Taurus, 1972.

. Los orígenes de la novela decimonónica, 1800-1830. Madrid: Taurus, 1973.

La novela española en el siglo XIX (hasta 1868). Madrid: Taurus, 1897.

Gimeno de Flaquer, C. "Influencia de la novela en la imaginación de la mujer." Antología de la prensa periódica isabelina escrita por mujeres (1843-1894). Edición de Í. Sánchez Llama. Cádiz: Servicio de Publicaciones de la Universidad de Cádiz, 2001. 267.

Grassi, Á. El copo de nieve. Edición, introducción y notas de Í. Sánchez Llama. Madrid: Castalia e Instituto de la Mujer, 1992. 
Loustau, L. R. “Canonicidad, valor literario y escritura femenina en El copo de nieve de Ángela Grassi." Lucero 6 (1995): 53-60.

Marco, J. "El costumbrismo español como reacción." La imagen de Andalucía en los viajeros románticos y Homenaje a Gerald Brenan. Málaga: Diputación Provincial de Málaga, 1987. 127-139.

Morales Sánchez, I. La novela como género. Tradición y renovación en la teoría literaria española del siglo XIX. Cádiz: Servicio de Publicaciones de la Universidad de Cádiz, 2000.

Pennac, D. Como una novela. Barcelona: Círculo de Lectores, 1993.

Romero Tobar, L. La novela popular española del siglo XIX. Barcelona: Ariel, 1976.

Sánchez Llama, Í. Galería de escritoras isabelinas. La prensa periódica entre 1833 y 1895. Madrid: Cátedra, Universitát de Valencia, Instituto de la Mujer, 2000.

Schor, N. George Sand and Idealism. Nueva York: Columbia University Press, 1993.

Sinués de Marco, Ma. del P. Un libro para las damas. Estudios acerca de la educación de la mujer. Madrid: Oficinas de la Ilustración Española y Americana, 1878.

Simón Palmer, Ma. del C. "Escritoras españolas del siglo XIX o el miedo a la marginalización." Anales de Literatura Española 2 (1983): 477-490.

Ynduráin, F. Galdós entre la novela y el folletín. Madrid: Taurus, 1970. 